\title{
When Cholera Came to Pibor
}

\section{Gisle Schmidt*}

Sofienbergt 3b, N-0551 Oslo, Norway

\section{Article Info}

\section{Article Notes}

Received: September 17, 2018

Accepted: October 292018

\section{*Correspondence:}

Dr. Gisle Schmidt, Sofienbergt 3b, N-0551 Oslo, Norway; Telephone No: +4747316561; Email: gschmid@online.no

C 2018 Schmidt G. This article is distributed under the terms of the Creative Commons Attribution 4.0 International License.
This is a story on how a 59-year-old family doctor comfortably based in Oslo, Norway experienced an outbreak of cholera when he in 2005 joined the MSF (Médecins Sans Frontières) for a 6-month mission to Pibor, a small remote village in South Sudan (Figure 1).

The area and the country just having emerged from a long and bloody civil war, was familiar with cholera where it is endemic and where epidemic outbreaks occur more or less regularly, mainly in the rainy season. Dirt roads often washed away during the rainy season, connect Pibor to neighbouring villages dotted far apart on the vast Savannah. A makeshift airfield, merely a clearing in the bush, allows for small aircrafts to land and take off when and if weather conditions allow and with no means of telecommunication apart from radio transmission and satellite telephone, we were left feeling pretty isolated from the outside world.

Just some months before my arrival, the MSF had established a small clinic based in tents, offering very basic primary health care services to the community. People were suffering from the hardships due to harsh surroundings, from the aftermath of the war and from the whole spectrum of diseases common in the tropics. Needs were vast.

In Jan 2006, we are in the dry season, a lorry, fully loaded with people set off from Juba, the capital, and after several hours on the



Figure 1: South Sudan 
dusty road, it arrives in Pibor. A young mother, passenger from the lorry, came to our clinic, bringing her 10-year-old, complaining of some slight watery diarrhea and vomit, but otherwise in good shape. No need to worry so far. However, the story becomes far more worrisome when she tells us about a two-year-old co-passenger on the lorry, who after a short history of severe diarrhea and vomit, passed out on the way. He was buried by the wayside.

The mother inquired whether we now thought there was a reason to be worried. Affirmative! Not for her child, who obviously would be doing well. She was aware of cholera cases in Juba, as were we. Could it be that the lorry, in fact, had imported the disease to our village, to an area lacking any kind of modern sanitation, with no proper latrines, the only source of drinking water being highly contaminated creeks and small rivers on their way to feed the White Nile?

Cholera is caused by the gram-negative comma-shaped Vibrio cholerae, a resilient organism having two main reservoirs, water and humans. It is transmitted through human faeces. Depending on the infectious dose and some other factors, it may cause very serious disease in about 1 of 20 infected, and a severely affected patient may succumb and die within hours of debut. The bacteria release an enterotoxin activating adenylate cyclase promoting the secretion of fluids and electrolytes through the intestinal epithelia, causing voluminous vomiting and diarrhea. Rehydration orally or intravenously is treatment of choice and it is nearly always efficient and adequate if the loss of fluid and electrolytes are fully replaced in time.

Our staff had no experience and none of us were trained to handle an outbreak of cholera, which could very well prove to be the imminent scenario we were facing. Assessing the situation, we agreed that we now had one probable index case, there was a truckload of people from an epidemic area spending hour with a very sick child who died on the road, spreading out through the village and its close surroundings. We decided to radio the MSF office in Nairobi who immediately forwarded our message to the headquarters in Brussels. The response was prompt and very clear: Isolate your patient and any other passenger on the truck, with or without symptoms, and we will come back to you with further notice! But alas, the boy had already returned home, some hygienic advice given to the mother. We had no possible means to reach him, nor any other of the passengers.

Soon after our call to Nairobi, obviously having caused alarm bells sounding in Brussels, we received HQs assessment: We must prepare for a cholera outbreak in the making. A "cholera kit" calibrated to fit our situation and our context will be shipped by air immediately, including trained and experienced personnel, tents and beds for setting up designated hospital facilities, supplies of ORS
(Oral rehydration salts) and IV fluids, hygienic articles like chlorine and soaps, buckets whatever the situation at hand demanded.

We were a bit taken aback. We had one possible index case, already home and well and out of reach. We were in fact nearly about to retract our alarm. But then, already a few hours later, we had our first real cholera patient. Four young men came to the clinic carrying their friend in a blanket, severely dehydrated, diarrhea and vomit pouring. Diarrhea greyish, watery just like described in the textbook. We had ample supplies of Ringers lactate and ORS in our dispensary, ready for use to treat the common diarrheal conditions, frequent in the area. But this proved to be a different situation all together. In order to rehydrate our young patient, we had to establish an IV line in both arms, shoving 5-6 liters of Ringer into his veins in the course of a few hours before getting him back in shape, sitting up, chatting with his friends. It was evening by then. We left one of the IV lines dripping during the night, but the next morning, he was almost back where we started. Thus, we learned and experienced the full force of cholera the hard way. Keep IV fluids flowing until diarrhea and vomit has subsided to an extent when oral substitution can be adequate, but under careful observation! During the next couple of days, and another 20 liters of IV fluids, diarrhea, and the vomit ceased. We had by then emptied a similar volume of grey whitish fluids in the latrine. The man had just been in close contact with one of the lorry passengers from Juba.

During the following days, patients kept pouring in (Figure 2). Some severely dehydrated, in need of IV rehydration, most of them, just moderately so, and getting well just by oral rehydration. We had learned our lesson, and kept them all under continuous, careful observation.

Our stock of IV fluids and ORS were coming close to depletion, when the announced airlift from Brussels arrived. Our team was supplied by incoming experienced

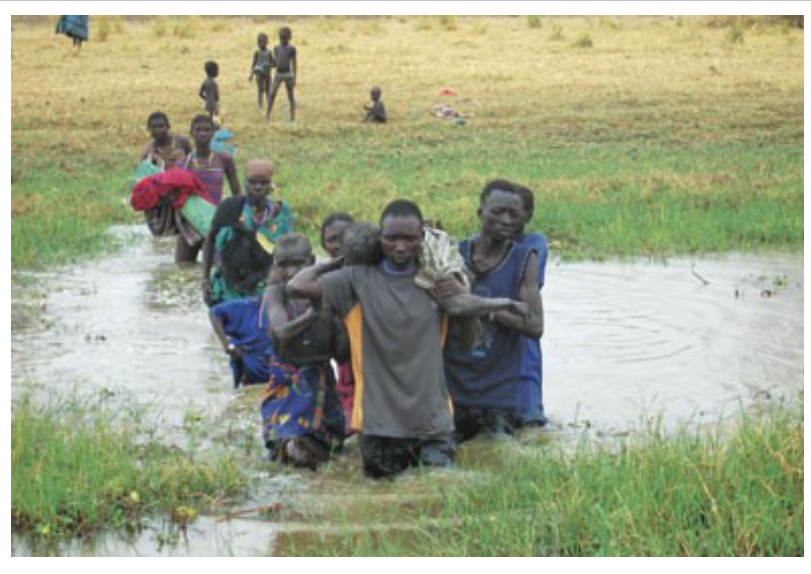

Figure 2: A severely dehydrated patient is brought to the clinic 




Figure 3: A cholera unit is established

experts, and we were all drilled and enabled to perform the necessary procedures and routines properly and safely. A new cholera unit, segregated and fenced off from the rest of our clinic, was erected in the course of the next few days (Figure 3). On accessing and exiting the unit, one had to pass through a chlorinated foot bath, and rinse hands in a similar solution.

Assessing degree of dehydration - triage - in the steadily incoming patients took place in the reception area. The least affected where given ORS and observed just long enough to make sure they could be returned home after having received treatment and hygienic instructions, in accordance with treatment plan A. Patient with signs of moderate dehydration able to compensate fluid and electrolyte loss with intake of ORS were observed in an outpatient area, and if and when rehydrated adequately, diarrhea and vomit under control, they were sent home under treatment plan B. If severely dehydrated on arrival or if oral rehydration proved to be insufficient, patients were transferred to treatment under plan C, as inpatients. They were placed on special cholera beds (their bottoms placed over a hole in the middle of the bed, a bucket underneath for passing of diarrhea, and a bucket on the side for the vomit), and one or two IV lines established. We became experts inserting venflons in nearly collapsed veins under dark skin (Figure 4). Within a week, our new unit was functioning well, able to handle 40 to 50 patients, staying on average around 3 to 4 days before returning home well and fit. Vaccination or medical treatment of staff and contacts was not an issue at the time.

We were running an outreach mini clinic, in Gumruk, a small village about $30 \mathrm{~km}$ from Pibor. Cases were reported also from there. We brought fluids and other supply along and established a small makeshift cholera unit. Local "scouts" were instructed to look for and report new cases and bring them to our unit. If too sick to be moved, we brought fluids to their compounds and started rehydrated them before bringing them to the clinic. The sickest we loaded in our land cruiser and brought to Pibor.

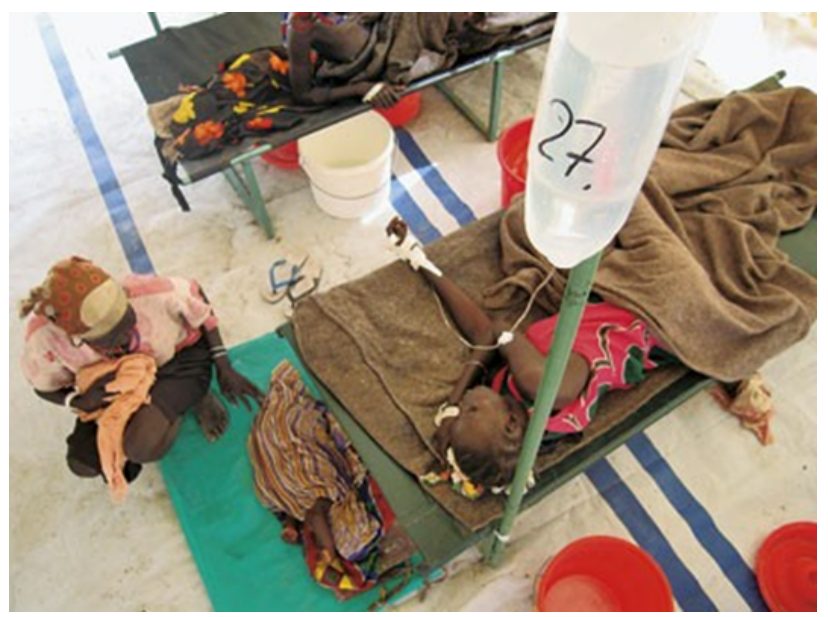

Figure 4: We are on the 27 th bottle of iv fluids

The Murle tribe, inhabiting this remote area, are cattle herders and pastoralists. In this very dry period of the year, a good portion of men and cattle had migrated to greener pastures before the outbreak. The migrants would be back by May or June.

On my leaving in early April, the number of patients had started to subside, but the unit was still in operation and vigilant. Thus far, we counted around 300 lives having been saved by our intervention, most of them, young and healthy. We lost only two. We had no reports of cases from other villages but Gumruk.

We had experienced a cholera outbreak that unlike former outbreaks in the area, had been contained and handled with a minimal loss of lives. Several coacting factors played in:

There was already a fully operational MSF clinic in the village, with support from a very professional and able backup in Nairobi and Brussels, with access to experienced personnel, supply and logistics ready to be activated on short notice.

The outbreak happened during the dry season, and our airfield was readily accessible. Moreover, in the rainy season, faeces and waste would more readily have been washed out into the unprotected water sources. A good portion of the villagers had migrated with their cattle before the outbreak. Villages far apart with modest communication between them prevented the outbreak from spilling over into the wider rural area. There was no warfare of violence going on at the time.

History has shown, that there would be worse to come in S Sudan. The country relapsed into a new bloody civil war in Dec. 2013. And in June 2016 an outbreak of cholera, also starting in Juba, eventually spread into the rural parts covering the whole country, adding more than 20000 cases and 436 deaths to the casualties and misery caused by the 
war. No new cases have been reported since Dec.2017. In Aug 2018, the rival parties signed (yet another!) peace agreement signalling their will and intention to join forces, promising to lead their young and perilled nation in a peaceful and constructive manner.

The youngest nation in our world has experienced a very a rocky start since independence was declared in 2011, as violence, famine, disease, including cholera, has taken a huge toll on its population. There might be more hardships ahead, including cholera outbreaks, unless or until the country gets its acts together, securing the lasting peace, building highly needed infrastructure and more robust institutions. 